\title{
Kinetics of Silica Particle Formation in Nonionic W/ 0 Microemulsions from TEOS
}

\author{
Chia-Lu Chang and H. Scott Fogler \\ Dept. of Chemical Engineering, The University of Michigan, Ann Arbor, MI 48109
}

\begin{abstract}
The kinetics of silica particle formation by the ammonia-catalyzed hydrolysis of tetraethyl orthosilicate (TEOS) in water-in-oil (W/O) microemulsions containing a nonionic surfactant was investigated using Fourier-transform infrared spectroscopy, transmission electron microscopy, and light-scattering techniques. The results show that TEOS hydrolysis and silica-particle growth occur at the same rate, indicating the growth of silica particles is rate-controlled by the hydrolysis of TEOS. The rate of TEOS hydrolysis in microemulsions is first order with respect to the concentration of aqueous ammonia ( $29 \mathrm{wt} . \% \mathrm{NH}_{3}$ ), but depends weakly on the concentration of water. Based on the fact that TEOS hydrolysis follows a nucleophilic $\left(S_{N} 2\right)$ substitution of the TEOS's ethoxy group with hydroxyl ion, the kinetic data suggest that both water and ammonia remain predominately in $W / O$ microemulsion droplets. The rate of TEOS hydrolysis also depends on the surfactant concentration that controls the molecular contact between hydroxyl ions and TEOS in the solution. Due to the reaction-controlled growth mechanism, the silica-particle size distribution retains virtually the same shape over the growth period. The final average size of silica particles can be varied from 26 to $43 \mathrm{~nm}$ by adjusting concentrations of water and surfactant. Increasing the water concentration decreases the average size and uniformity of silica particles. For a given water concentration, the smallest and most uniform silica particles are produced at intermediate water-to-surfactant molar ratios (about 1.9). The results are discussed in terms of the effect of water concentration on the stability of the hydrolyzed silica reacting species during the nucleation of particles and of the water-to-surfactant molar ratio on the compartmentalization of silica species in microemulsions.
\end{abstract}

\section{Introduction}

Water-in-oil (W/O) microemulsion solutions (also called reverse micellar solutions) are transparent, isotropic liquid media with a continuous oil component and a discrete aqueous component that is thermodynamically compartmentalized by surfactants into nanometer-sized liquid entities. These surfactant-covered aqueous microentities, called microemulsion droplets, offer a unique microenvironment for inorganic precipitation reactions; that is, they act not only as microreactors for hosting the reaction but also as steric stabilizers to inhibit the aggregation of polymeric reacting species during the reaction period. As a result, inorganic precipitation in W/O microemulsions usually generates colloidal particles of

\footnotetext{
Correspondence concerning this article should be addressed to H. S. Fogler.
}

nanometer scale (less than $100 \mathrm{~nm}$ ), which are much smaller than those synthesized in normal aqueous solutions. Indeed, microemulsion synthesis routes have been used to make nanoparticles of numerous materials, including metals, metal oxide, metal boride, metal sulfide, metal halide, and metal carbonate (Fendler, 1987; Nagy et al., 1989; Robinson et al., 1989; Ward and Friberg, 1989; Sugimoto, 1987; Kon-no, 1993).

In this study, the synthesis of silica $\left(\mathrm{SiO}_{2}\right)$ particles from tetraethyl orthosilicate (TEOS, $\left.\mathrm{Si}\left(\mathrm{OC}_{2} \mathrm{H}_{5}\right)_{4}\right)$ was carried out in a nonionic W/O microemulsion medium. Reactions involved in this silica synthesis include the hydrolysis of TEOS and the condensation (polymerization) of the hydrolyzed silica species (monomeric and polymeric silica reacting units) in the presence of a base catalyst, ammonia, as shown below: 
[Hydrolysis]

$$
\equiv \mathrm{Si}-\mathrm{OR}+\mathrm{H}_{2} \mathrm{O} \Leftrightarrow \equiv \mathrm{Si}-\mathrm{OH}+\mathrm{ROH}
$$

[Alcohol condensation]

$$
\equiv \mathrm{Si}-\mathrm{OR}+\equiv \mathrm{Si}-\mathrm{OH} \Leftrightarrow \equiv \mathrm{Si}-\mathrm{O}-\mathrm{Si} \equiv+\mathrm{ROH} .
$$

[Water condensation]

$$
\equiv \mathrm{Si}-\mathrm{OH}+\equiv \mathrm{Si}-\mathrm{OH} \Leftrightarrow \equiv \mathrm{Si}-\mathrm{O}-\mathrm{Si} \equiv+\mathrm{H}_{2} \mathrm{O} .
$$

[Overall reaction]

$$
\mathrm{Si}(\mathrm{OR})_{4}+2 \mathrm{H}_{2} \mathrm{O} \stackrel{\mathrm{OH}^{-}}{\longrightarrow} \mathrm{SiO}_{2} \downarrow+4 \mathrm{ROH} .
$$

where $\mathrm{R}$ is $\mathrm{C}_{2} \mathrm{H}_{5}$.

\section{Previous studies of silica formation in $W / O$ microemulsion solutions}

The formation of silica particles from TEOS has been studied using ionic and nonionic W/O microemulsions (Yanagi et al., 1986; Yamauchi et al., 1989; Espiard et al., 1990; Osseo-Asare and Arriagada, 1990, 1992; Arriagada, 1991; Arriagada and Osseo-Asare, 1995). Previous results indicate that silica particles synthesized in W/O microemulsion solutions generally have average sizes in the range between 30 and $70 \mathrm{~nm}$. The stability and final size distribution of synthesized silica particles are affected by the concentrations of water and surfactant as well as the characteristics of the surfactants.

Suspensions of silica particles with a narrow size distribution have been synthesized by hydrolyzing TEOS in the ternary systems containing aqueous ammonia ( $29 \mathrm{wt} . \% \mathrm{NH}_{3}$ ), cyclohexane, and nonionic polyoxyethylene nonylphenyl ether surfactants (which will be abbreviated as NP $x$, where $x$ is the average number of oxyethylene groups per surfactant molecule). Using nonionic NP6 surfactant, Yanagi et al. (1986) obtained uniform silica particles with an average diameter around 40 to $50 \mathrm{~nm}$. The size of synthesized particles in general decreased with increasing the concentration of water (Kon-no, 1993). Arriagada and Osseo-Asare made an extensive study on the silica-particle formation in W/O microemulsions with NP5 surfactant (Osseo-Asare and Arriagada, 1990, 1992; Arriagada, 1991). The synthesized silica particles were also fairly uniform and ranged from 35 to 70 nanometer in diameter. Silica particles with the smallest size and narrowest distribution were obtained at an intermediate water-tosurfactant molar ratio (e.g., 1.4), whereas both the size and dispersity of silica particles increased at both higher and lower water-to-surfactant molar ratios (e.g., 3.5 and 0.5 , respectively) (Osseo-Asare and Arriagada, 1990). In addition, when the initial water concentration approached the solubility limit (the phase boundary), ethanol produced from TEOS hydrolysis during the reaction resulted in phase separation of reaction media into a microemulsion and a second phase of bulk water that subsequently initiated a new nucleation stage. At the other limit, if the initial water-to-TEOS molar ratio approached the stoichiometric ratio of the overall silica forma- tion reaction (i.e., 2), silica particles became unstable and precipitated. This result indicated that the residual water was necessary to stabilize silica particles in microemulsions (Osseo-Asare and Arriagada, 1992). Residual water acted as an intermediate medium that hydrogen-bonded both surfactant molecules and the surface of silica particles. As a result, the surfactants attached themselves to the surface of silica particles and sterically stabilized them from flocculating.

The synthesis of silica particles was also carried out in a W/O microemulsion containing the anionic sodium (2-ethylhexyl) sulfonate (AOT) surfactant. However, the resulting particles were highly polydisperse as a consequence of continuous nucleation proceeding over the reaction period. Due to the hydrolysis of AOT surfactant, these particles became unstable in the microemulsions, and eventually flocculated and precipitated out as gels with a microporous structure (Arriagada and Osseo-Asare, 1995; Yamauchi et al., 1989).

Previous studies accounted for the effect of water and surfactant concentrations on the growth of silica particles via the hydrolysis of TEOS in W/O microemulsions; however, the reaction kinetics and mechanism of particle growth have not been delineated and are the focus of this article. It is known that TEOS molecules, predominantly solubilized in the oil phase of microemulsions, diffuse to the surfactant layer at oil-water interfaces and are hydrolyzed by water to form silanol groups ( $\mathrm{Si}-\mathrm{O}^{-}$or $\mathrm{Si}-\mathrm{OH}$ ) (Yanagi et al., 1986). Consequently, these hydrolyzed TEOS molecules are preferentially retained in the microemulsion droplets and condensed into polymeric species. After reaching a critical size, these polymeric species become nuclei that further grow into silica spheres by adsorbing hydrolyzed TEOS molecules and small polymeric silica species. Arriagada (1991) studied the rate of silica-particle growth by following the evolution of silica-particle-size distributions measured from TEM micrographs. It was found that the rate of silica-particle growth was sufficiently slow that $100 \mathrm{~h}$ were required to reach the final particle size. Because the rate of silica-particle growth increased with increasing surfactant concentration, it was proposed that the particle-growth rate was influenced by the hydrolysis of TEOS, which involved the partitioning of TEOS between the oil pseudophase and the microemulsion droplet pseudophase. However, there is still no systematic investigation of the rate of TEOS hydrolysis, the relationships between the TEOS hydrolysis rate and the silica-particle growth rate, and the influence of the concentration of water and ammonia on the kinetics of silica-particle growth in microemulsions.

\section{Related studies on the kinetics of silica-particle formation in alcohol media}

The kinetics and mechanism of silica-particle formation by the base-catalyzed hydrolysis of TEOS in alcohol media have been investigated extensively (Aelion et al., 1950; Stoer et al., 1968; Brinker and Scherer, 1989; Bergna, 1994). These studies provide valuable insight into the growth of silica particles in microemulsions and are briefly reviewed below.

The kinetics of TEOS hydrolysis in methanol solutions catalyzed by dilute sodium hydroxide $(\mathrm{NaOH})$ was studied by Aelion and coworkers (1950) using the Karl-Fischer titration method. They found that the base-catalyzed hydrolysis of 
TEOS had a first-order dependence on the concentrations of both TEOS and hydroxyl ion $\left(\mathrm{OH}^{-}\right)$, that is,

$$
-\frac{d[\text { TEOS }]}{d t}=k\left[\mathrm{TEOS}_{[}\left[\mathrm{OH}^{-}\right] .\right.
$$

On the basis of this study, the base-catalyzed TEOS hydrolysis reaction was proposed as a nucleophilic $\left(S_{N} 2\right)$ substitution reaction involving the displacement of the ethoxy $\left(-\mathrm{OC}_{2} \mathrm{H}_{5}\right)$ group of TEOS by hydroxyl ion through a pentacoordinate transition state. However, the kinetics of TEOS hydrolysis in alcohol media with a weak base catalyst, ammonia, appeared more complicated as the rate of TEOS hydrolysis depended upon $\left[\mathrm{H}_{2} \mathrm{O}\right]$ and $\left[\mathrm{NH}_{3}\right]$, which had apparent reaction orders of 1.5 and 1, respectively (Byers et al., 1987; Bogush and Zukoski, 1991; Van Blaaderen et al., 1992).

The kinetics of silica particle growth in alcohol media from the ammonia-catalyzed hydrolysis of TEOS has also been studied (Harris et al., 1990; Matsoukas and Gulari, 1988; Bogush and Zukoski, 1991; Van Blaaderen et al., 1992). It was found that in alcohol media both the rates of silica-particle growth and TEOS hydrolysis were first order with almost the same specific rate constant, indicating that silica-particle growth was reaction-controlled by the hydrolysis of TEOS (Matsoukas and Gulari, 1988). Because of this reaction-controlled growth, silica particles with smooth surfaces and narrow size distributions were formed in the early particle-growth period through the addition of monomeric and oligomeric hydrolyzed TEOS species. Nevertheless, in the nucleation period, the formation of silica nuclei advanced through the coagulation of primary silica particles (polymeric silica species), which was controlled by the surface-charge density of the particles and the ionic strength of the alcohol media (Bogush and Zukoski, 1991; Van Blaaderen et al., 1992).

In this study, we carried out a systematic investigation of the kinetics and mechanism of silica-particle growth in a W/O microemulsion system containing heptane, ammonia, water, and a nonionic polyoxyethylene (4) nonylphenyl ether (NP4) surfactant. Three experimental techniques were used. Fourier-transform infrared spectroscopy (FTIR) was used to quantify the rate of TEOS hydrolysis, while transmission electron microscopy (TEM) and light-scattering (LS) methods were used to measure the size distribution and the growth rate of silica particles. The scope of this study includes the comparison of the rates of TEOS hydrolysis and silica-particle growth, the influence of the concentrations of ammonia, water, and surfactant on the rate of TEOS hydrolysis, as well as the effects of water and surfactant concentrations on the size and dispersity of synthesized silica particles.

\section{Experimental Studies}

\section{Sample preparation}

The nonionic NP4 surfactant, Triton N42 (Rohm \& Haas Co.), was used as received to prepare $\mathrm{W} / \mathrm{O}$ microemulsion solutions. This surfactant is a polydisperse mixture of polyoxyethylene nonylphenyl ether with an average of four oxyethylene groups per molecule $\left(n-\left(\mathrm{C}_{9} \mathrm{H}_{19} \mathrm{O}\left(\mathrm{OC}_{2} \mathrm{H}_{4}\right)_{4} \mathrm{OH}\right.\right.$, MW: 396.5). Tetraethyl orthosilicate (TEOS) $\left[\mathrm{Si}\left(\mathrm{OC}_{2} \mathrm{H}_{5}\right)_{4}\right.$, MW: 208.33] with $99.999 \%$ purity (Aldrich Co.), reagent grade heptane, and aqueous ammonia $\left(\mathrm{NH}_{4} \mathrm{OH}\right)$ solution with 71 wt. \% water and 29 wt. \% ammonia $\left(\mathrm{NH}_{3}\right)$, were used without further purification. The aqueous ammonia solution acts as both the reactant $\left(\mathrm{H}_{2} \mathrm{O}\right)$ and the catalyst $\left(\mathrm{NH}_{3}\right)$ for the hydrolysis of TEOS. To prepare $\mathrm{W} / \mathrm{O}$ microemulsion solutions, aqueous ammonia and purified water (deionized at 18 Mohm) were added to the heptane solution containing premixed NP4 surfactant; the resulting mixture was gently shaken till completely transparent. TEOS hydrolysis and silica-particle formation began immediately after TEOS was added to the prepared microemulsion solution. The entire reaction was carried out at temperature $22^{\circ} \mathrm{C}$ in a tightly capped Teflon tube reactor that had negligible adsorption and absorption of the components in the solution.

\section{Fourier-transform infrared spectroscopic measurement}

Fourier-transform infrared spectroscopy (FTIR) was used to study the kinetics of TEOS hydrolysis in microemulsions. The concentrations of TEOS, ethanol, and water were quantified from the intensity of the absorption bands located at 795 and $967 \mathrm{~cm}^{-1}$ (Si-O-C stretching), 882 and $1,050 \mathrm{~cm}^{-1}$ (C-C-O stretching), and $1,640 \mathrm{~cm}^{-1}(\mathrm{H}-\mathrm{O}-\mathrm{H}$ deformation), respectively. These bands can be used to quantify the concentration of reaction species in that the absorption intensities of these bands are significantly strong compared with the absorption background contributed by heptane and NP4 surfactant. The transmission FTIR spectra of microemulsion solutions were measured using a single-beam Mattson CYGNUS 100 FTIR spectrophotometer equipped with a wide-band mercury-cadmium-telluride (MCT) detector. The scattering of the incident beam by silica particles was negligible because particles were dilute in solution and had diameters (about 40 $\mathrm{nm}$ ) much shorter than the wavelength of infrared light. A triangular apodization method was employed for Fourier transforming the interferogram. The solution was accommodated in a sample holder with a pair of zinc selenide ( $\mathrm{ZnSe}$ ) windows and a 0.2 -mm-thick spacer. In general, the experimental error in quantifying TEOS concentration during the early and middle stages of reaction was less than $10 \%$ and became higher in the final reaction stage due to the diminishing intensity of TEOS's absorption bands.

\section{Transmission electron microscopic analysis}

The size and morphology of silica particles synthesized in microemulsions were investigated using a Jeol 2000 FX transmission electron microscope. The specimen for TEM analysis was prepared by placing a small amount of sample solution on a 200-mesh carbon-coated copper grid (Structure Probe, $3520 \mathrm{C}$ ). Because oven-drying did not effectively evaporate, the residual NP4 surfactant remained on the copper grid; dichloromethane was used to wash it off. The particle diameters, $D$, of approximate 200 silica particles were measured from the enlarged computer image of the TEM micrographs. From the particle-size distribution, the average diameter, $\langle D\rangle$, and the standard deviation, $\sigma$, defined by

$$
\sigma=\left[\left\langle D^{2}\right\rangle-\langle D\rangle^{2}\right]^{1 / 2}
$$

were calculated. 


\section{Light-scattering measurements}

The rate of silica-particle growth in alcohol solutions has been deduced from the increase in the light intensity scattered from solutions (Harris et al., 1990; Matsoukas and Gulari, 1988; Van Blaaderen et al., 1992). In this study, the intensity of light scattered from solutions containing dilute growing silica particles can be approximated as

$$
\langle I\rangle=\langle I(0)\rangle+\alpha_{p}^{2} V_{p}^{2} C_{p} F_{p}
$$

where $\langle I\rangle$ is the scattered light intensity of solutions; $\langle I(0)\rangle$ is $\langle I\rangle$ at the start of silica formation; $\alpha_{p}, V_{p}, C_{p}$ are the polarizability, volume, and concentration of silica particles in solution, respectively.

The form factor of silica particles, $F_{p}$, can be approximated by the Guinier law as

$$
F_{p}(q D)=\exp \left(-\frac{(q D)^{2}}{20}\right)
$$

where $D$ is the diameter of silica particles and $q$ is the magnitude of the scattering vector. The instrument used in this study included a 2-W argon ion laser (Lexel Model 95) generating a light of $514.5 \mathrm{~nm}$ in wavelength and a photon-multiplier tube connected with a 136-channel digital correlator (Brookhaven BI2030).

\section{Kinetics analysis of TEOS hydrolysis and silica-particle growth}

The concentration of TEOS obtained from FTIR spectroscopic measurement was used to deduce the kinetics of TEOS hydrolysis. In this study, the concentration of water was always kept significantly in excess in order to stabilize silica particles in the solution. Therefore, the rate of TEOS hydrolysis can be treated as first order with respect to the TEOS concentration that follows an exponential decay

$$
\frac{[\mathrm{TEOS}](t)}{[\mathrm{TEOS}](0)}=\exp \left(-k_{h} t\right)
$$

where [TEOS] $(t)$ and [TEOS](0) are the concentrations of TEOS at reaction time $t$ and at the start of reaction, respectively; $k_{h}$ is the specific rate constant for TEOS hydrolysis.

The rate of silica-particle growth can be deduced from the increase in the volume of silica particles measured by TEM and light-scattering methods. For a first-order reaction, the rate of silica-particle growth follows

$$
1-\frac{V_{p}(t)}{V_{p}(\infty)}=\exp \left(-k_{c} t\right)
$$

where $k_{c}$ is the specific rate constant for silica-particle growth; $V_{p}(t)$ and $V_{p}(\infty)$ are the volume of silica particles at time $t$ and at the end of reaction, respectively. For lightscattering measurements, Eq. 10 is reformulated as

$$
1-\left(\frac{F_{p}(\infty)(\langle I(t)\rangle-\langle I(0)\rangle)}{F_{p}(t)(\langle I(\infty)\rangle-\langle I(0)\rangle)}\right)^{1 / 2}=\exp \left(-k_{c} t\right)
$$

through Eq. 7, where $\langle I(0)\rangle,\langle I(t)\rangle$, and $\langle I(\infty)\rangle$ are the scattered intensity of solution at the start, at time $t$, and at the end of reaction, respectively; $F_{p}(t)$ and $F_{p}(\infty)$ are the form factor of silica particles at time $t$ and at the end of reaction, respectively (Chang, 1995).

\section{Results and Discussion \\ Phase diagram of the ternary NP4/water (aqueous ammonia)/heptane system}

In this study, silica particles were synthesized at $22^{\circ} \mathrm{C}$ in a W/O microemulsion containing NP4 surfactant, heptane, ammonia, and water. The solution composition necessary to form a single-phase $\mathrm{W} / \mathrm{O}$ microemulsion at this temperature was investigated first. Figure 1 shows the phase diagram of both NP4/water/heptane and NP4/aqueous ammonia/heptane systems. The single-phase microemulsion region is bounded by the solubilization curve beyond which phase separation results in a saturated microemulsion phase and a second aqueous phase. Both water and aqueous ammonia are not soluble in heptane until the NP4 surfactant concentration is increased to 1.8 wt. \% (i.e., $0.037 \mathrm{M}$ ). Above this NP4 concentration, the amounts of both water and aqueous ammonia solubilized increase with increasing NP4 concentration. In general, the solubility of water is about 1.5 times greater than that of aqueous ammonia. The lower solubility of aqueous ammonia can be attributed to a smaller degree of hydration of the surfactant head group layer on the microemulsion droplet. Ammonia molecules and hydroxide ions may act as lyotropic components, weakening the water-surfactant interaction or disrupting the hydrogen-bonding structure of pure water (Arriagada, 1991).

\section{Time evolution of TEOS hydrolysis and silica-particle growth}

FTIR, TEM, and LS techniques were used to study the rates of TEOS hydrolysis and silica-particle growth in a single-phase W/O (aqueous ammonia-in-heptane) microemulsion with the following composition: $[\mathrm{NP} 4]=0.126 \mathrm{M}$;

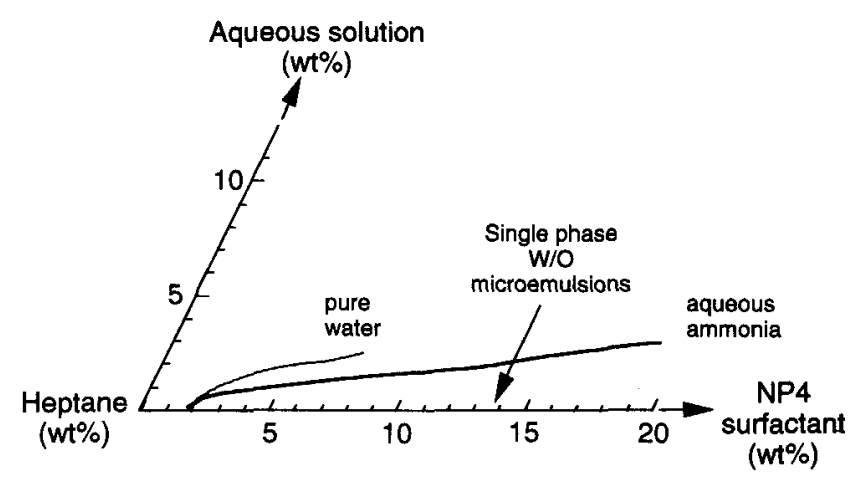

Figure 1. Phase diagrams of ternary NP4 surfactant/ aqueous phase/heptane systems.

The aqueous phase included pure water and aqueous ammonia (29 wt. \% $\mathrm{NH}_{3}$ ). 


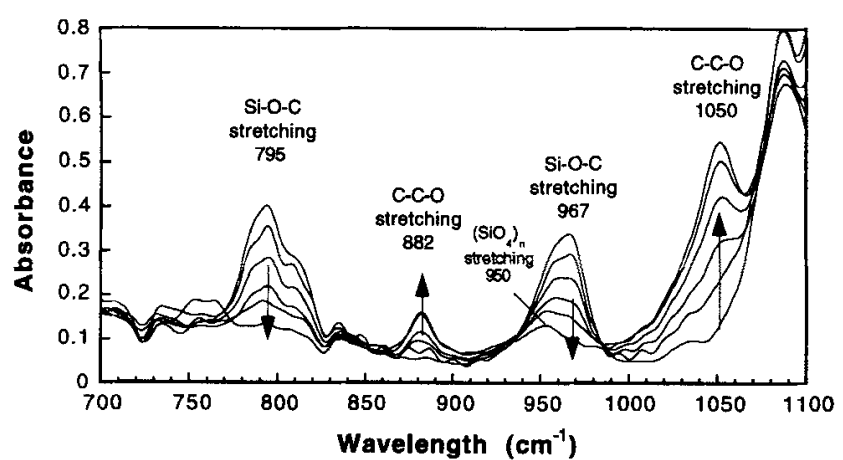

(a)

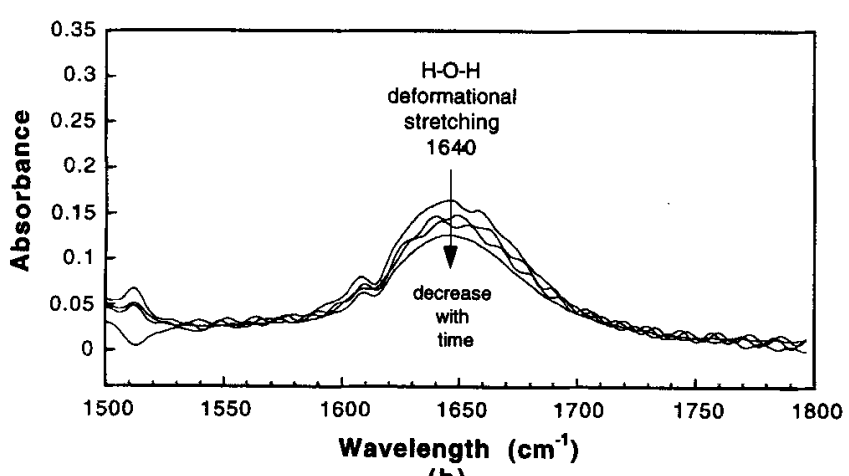

(b)

Figure 2. FTIR spectra of a microemulsion during TEOS hydrolysis and condensation.

The initial solution contained heptane solvent, $0.126 \mathrm{M} \mathrm{NP4}$, $0.0357 \mathrm{M}$ TEOS, $0.104 \mathrm{M} \mathrm{NH}_{3}$, and $0.235 \mathrm{M} \mathrm{H}_{2} \mathrm{O} \mathrm{M}$. The background subtracted was the FTIR spectrum of a heptane solution with $0.126 \mathrm{M} \mathrm{NP4}$ surfactant. The reaction time for each spectrum is shown in Figure 3.

$[$ TEOS $]=0.0357 \mathrm{M} ;\left[\mathrm{NH}_{3}\right]=0.104 \mathrm{M} ;$ and $\left[\mathrm{H}_{2} \mathrm{O}\right]=0.235 \mathrm{M}$ ( $\mathrm{M}$ is $\mathrm{mol} / \mathrm{dm}^{3}$ ).

Hydrolysis of TEOS. Figures $2 \mathrm{a}$ and $2 \mathrm{~b}$ show a typical evolution of the FTIR spectra of this microemulsion sample during TEOS hydrolysis. As shown in Figure 2a, the absorption bands of TEOS's Si-O-C group located at both 795 and 967 $\mathrm{cm}^{-1}$ decrease with the reaction time and eventually disappear, indicating that TEOS has been completely reacted. The formation of ethanol is seen by the increase of the ethanol's $\mathrm{C}-\mathrm{C}-\mathrm{O}$ stretching bands located at 882 and $1,050 \mathrm{~cm}^{-1}$ with the reaction time. Note that the small absorption peak at 950 $\mathrm{cm}^{-1}$ remains unchanged during TEOS hydrolysis, which most likely corresponds to the vibration of $\left(\mathrm{SiO}_{4}\right)_{n}$ groups (Colthup et al., 1990). The consumption of water is observed in Figure $2 b$ from the decrease of the $1,640 \mathrm{~cm}^{-1}$ band for the $\mathrm{H}-\mathrm{O}-\mathrm{H}$ deformational vibration with the reaction time. However, the decrease of this $1,640 \mathrm{~cm}^{-1}$ band is not as significant as that of TEOS due to the initial excessive amount of water. Moreover, it is known that $\mathrm{RSi}(\mathrm{OH})_{n}$ has a strong $\mathrm{Si}-\mathrm{OH}$ absorption band located between 910 and $830 \mathrm{~cm}^{-1}$. The lack of a noticeable $\mathrm{Si}-\mathrm{OH}$ band in Figure 2a suggests that most of the TEOS molecules, immediately after being hydrolyzed, condense into polymeric silica species (which surface may still be hydrated).

The concentrations of TEOS, ethanol, and water at different reaction times were calculated from the intensities of the

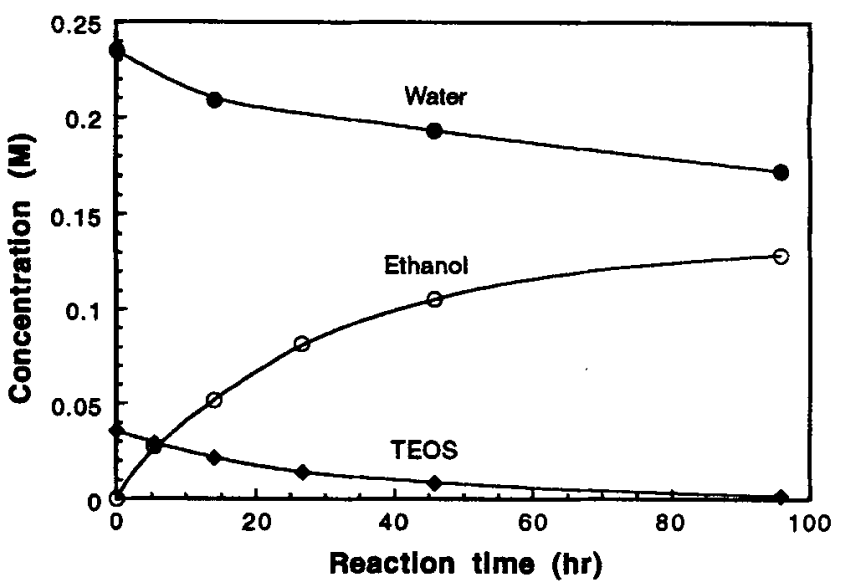

Figure 3. Concentrations of TEOS, $\mathrm{C}_{2} \mathrm{H}_{5} \mathrm{OH}$, and $\mathrm{H}_{2} \mathrm{O}$ during TEOS hydrolysis and condensation.

Data were measured by the absorbance of $967,1,050$ and $1,640 \mathrm{~cm}^{-1}$ bands in Figure 2 .

$967,1,050$ and $1,640 \mathrm{~cm}^{-1}$ bands, respectively. As illustrated in Figure 3, the TEOS concentration declines exponentially while the ethanol concentration increases exponentially. Over the reaction period, the increase in $\left(\mathrm{C}_{2} \mathrm{H}_{5} \mathrm{OH}\right)$ is approximately four times greater than the decrease in (TEOS), which is consistent with the ethanol-to-TEOS stoichiometric ratio in the TEOS hydrolysis reaction. The concentration of water decreases by $0.063 \mathrm{M}$ from $0.235 \mathrm{M}$ to $0.172 \mathrm{M}$ over the reaction period. This decrease in water concentration is approximately twice the initial concentration of TEOS, $0.0357 \mathrm{M}$. In summary, FTIR spectroscopic analysis provided quantitative information on the consumption of TEOS and water and the production of ethanol from the hydrolysis of TEOS in microemulsions.

Growth of Silica Particles. Transmission electron microscopy and light-scattering measurements were used to study the growth of silica particles in conjunction with the TEOS hydrolysis experiments discussed earlier. Figure 4 shows TEM micrographs of silica particles at different reaction times. These silica particles predominately attach directly to the surface of the TEM copper-grid specimen without forming multilayers or aggregates of particles, indicating that silica particles were dispersed well in the original solution. These silica particles are virtually spherical even though the hydrolysis reaction is carried out for less than $2 \mathrm{~h}$. The size distributions of silica particles grown at different reaction times are shown in Figure 5. These size distributions appear to have similar single-mode profiles, with $97 \%$ of the silica particles spanning a range of $12 \mathrm{~nm}$. The average size, $\langle D\rangle$, and the standard deviation, $\sigma$, of these size distributions are shown in Figure 6. The measured $\langle D\rangle$ value shows that silica particles grow quickly during the initial reaction period and then gradually level off at the final size of $39 \mathrm{~nm}$. The measured $\sigma$ value increases slightly from $1.5 \mathrm{~nm}$ at $1.7 \mathrm{~h}$ to $1.9 \mathrm{~nm}$ at $6 \mathrm{~h}$ and remains essentially constant at $1.9-2.1 \mathrm{~nm}$ afterwards. As a result, the normalized standard deviation, $\sigma\langle\langle D\rangle$, of silica particles decreases from $10 \%$ at $1.7 \mathrm{~h}$ after the start of reaction to $5 \%$ at the end of reaction.

The preservation of the particle-size distribution shape and standard deviation over the reaction period indicates that the 


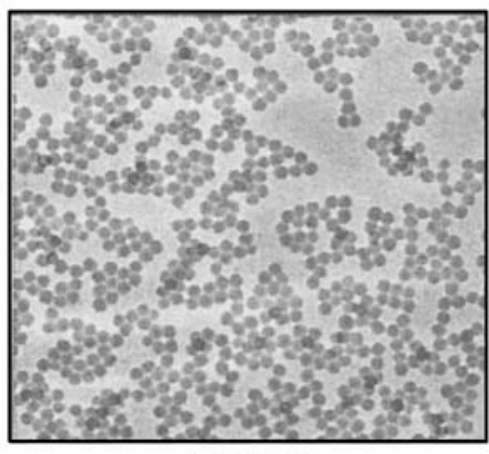

1.7 hours

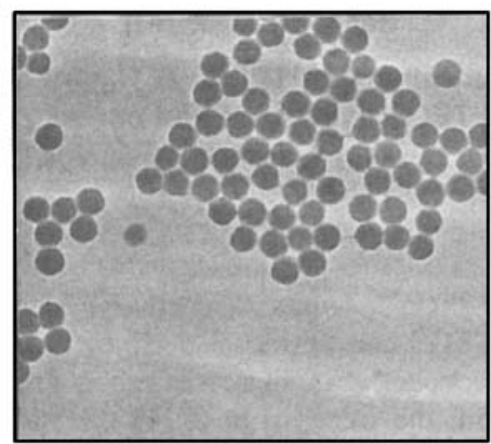

25.36 hours

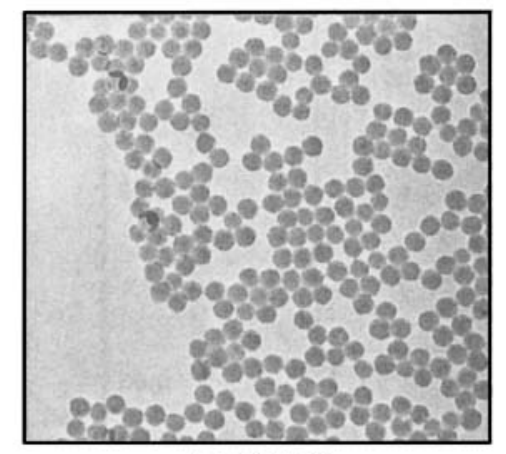

5.87 hours

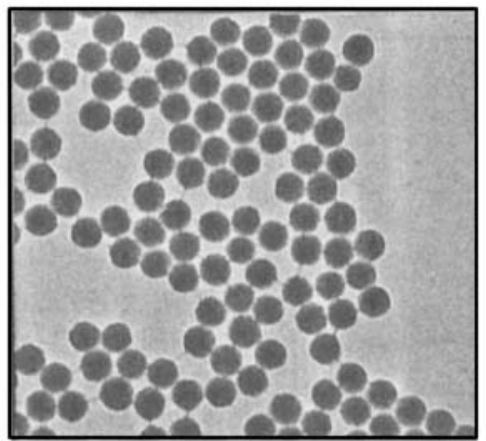

47.36 hours

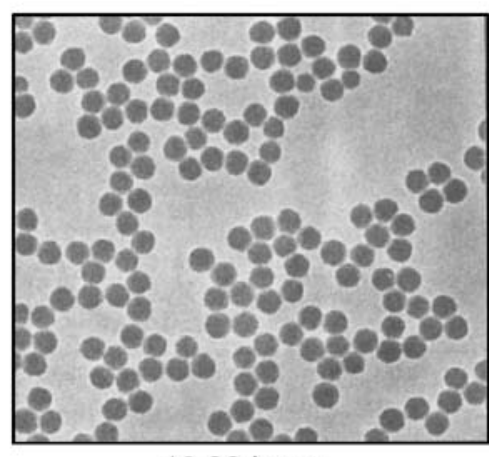

13.32 hours

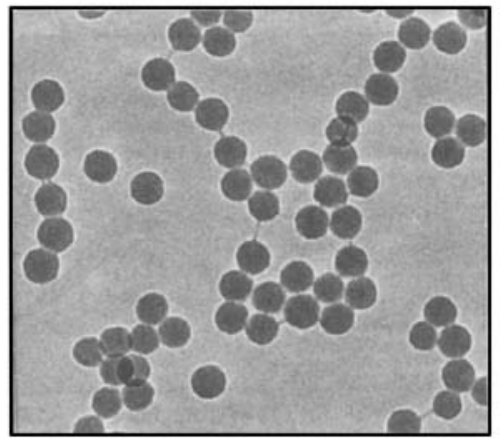

240.0 hours

Figure 4. TEM micrographs showing the growth of silica particles during TEOS hydrolysis.

The initial microemulsion composition is shown in Figure 2. The residual NP4 surfactant can be seen by thin threads between silica particles.

growth of silica particles follows a reaction-controlled behavior in the sense that the rate of increase of the particle size is independent of the diameter of particles. On the other hand, for the diffusion-controlled growth, neither the particle-size

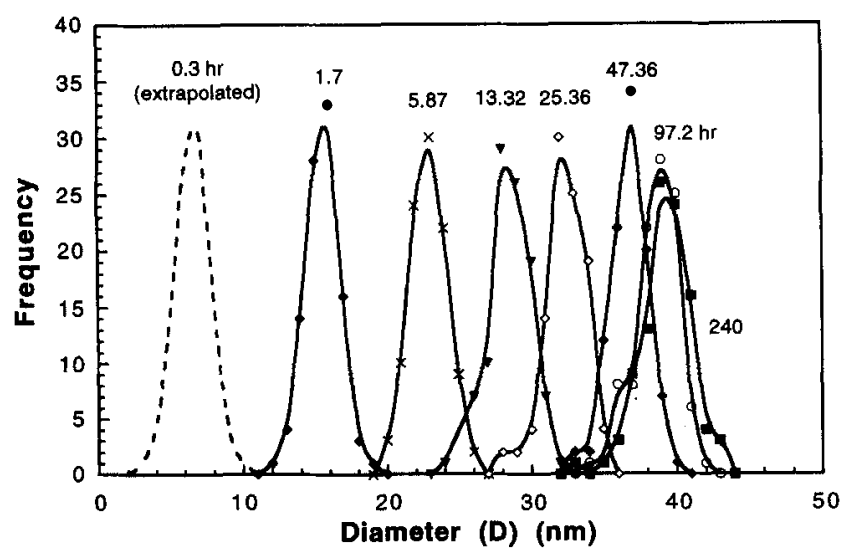

Figure 5. Size distribution of silica particles grown in a microemulsion during TEOS hydrolysis.

The initial microemulsion composition is shown in Figure 2. The reaction time (hour) is illustrated at above each distribution profile. The solid profiles are size distributions measured from TEM micrographs in Figure 4. The dashed profile is an extrapolated distribution achievable at the earliest reaction time by assuming a size-independent particle growth. distribution shape nor the standard deviation is preserved (Dirksen and Ring, 1991). This size-independent growth indicates that the exchange of hydrolyzed silica reacting species among microemulsion droplets is sufficiently fast compared with the condensation of reacting species to the growing particles. As a result, the reacting species maintain an even dis-

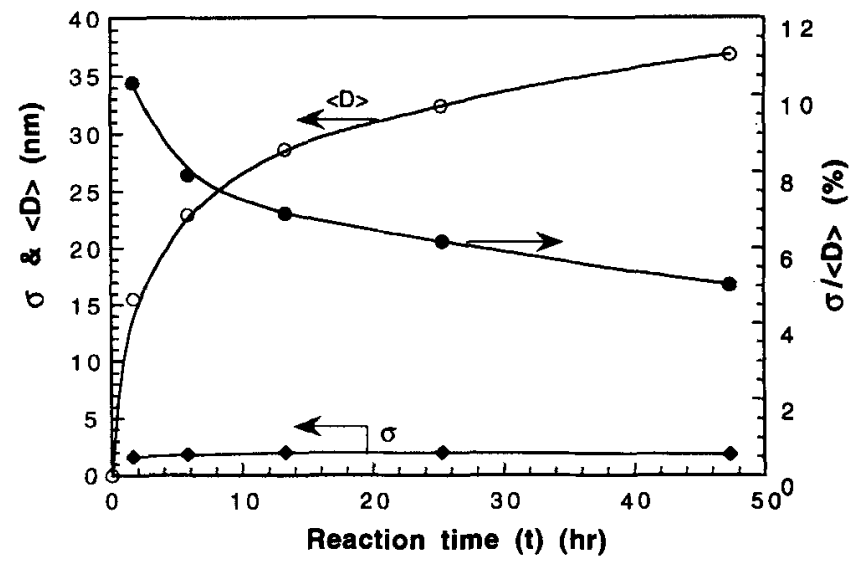

Figure 6. Number average diameter, $\langle D\rangle$, standard deviation, $\sigma$, and normalized standard deviation, $\boldsymbol{\sigma}\langle\boldsymbol{D}\rangle$, of silica particles during TEOS hydrolysis.

Results were calculated from the data shown in Figure 5. 
tribution over all droplets irrespective of the size of the growing particles therein, and condense onto silica-particle surfaces at a size-independent rate. The fast intermicellar exchange of hydrolyzed silica species in nonionic W/O microemulsions can be attributed to the micellar fusion-fission process (for hydrolyzed species resident in microemulsion droplet cores) and the matter exchange upon contact of surfactant layers around different droplets (for hydrolyzed species bound to surfactant layers) (Clark et al., 1990; Bommarius et al., 1990). Using microemulsions containing cyclohexane and NP5 surfactant, Arriagada (1991) also observed that the standard deviation of silica-particle size remained unchanged during growth; however, the time evolution of the particle-size distribution was not delineated.

The size-independent growth characteristics also implies that the earliest possible size distribution for the first $97 \%$ of silica particles nucleated could be represented by the dashed profile in Figure 5. This dashed profile, ranging from 0 to 12 $\mathrm{nm}$, preserves the shape of particle-size distributions obtained experimentally (solid profiles). The integrated area under the dashed profile indicates that the minimum time period for nucleating these silica particles was about 15-20 minutes. Note that the other $3 \%$ of silica particles appearing in the left side tail of the size-distribution profile would be most likely nucleated at later reaction times. The size-independent growth phenomena also suggest that the distribution profile of the final particle size is a record of the silica particle nucleation process. In general, particle formation in microemulsions involves the condensation of reacting species through intramicellar (internal micellar) collisions and intermicellar matter exchange. Because the number of synthesized silica particles was less than that of microemulsion droplets by three to four orders of magnitude, the nucleation of silica particles in nonionic W/O microemulsions is carried out mainly through the condensation of silica reacting species that exchange between microemulsion droplets (Arriagada, 1991). The silica reacting species, after reaching a critical size, become nuclei, which then adsorb small species to their surfaces to grow into individual particles.

Light-scattering measurements were used to study the growth of silica particles in the same microemulsion solution as used in the FTIR and TEM studies. As shown in Figure 7,

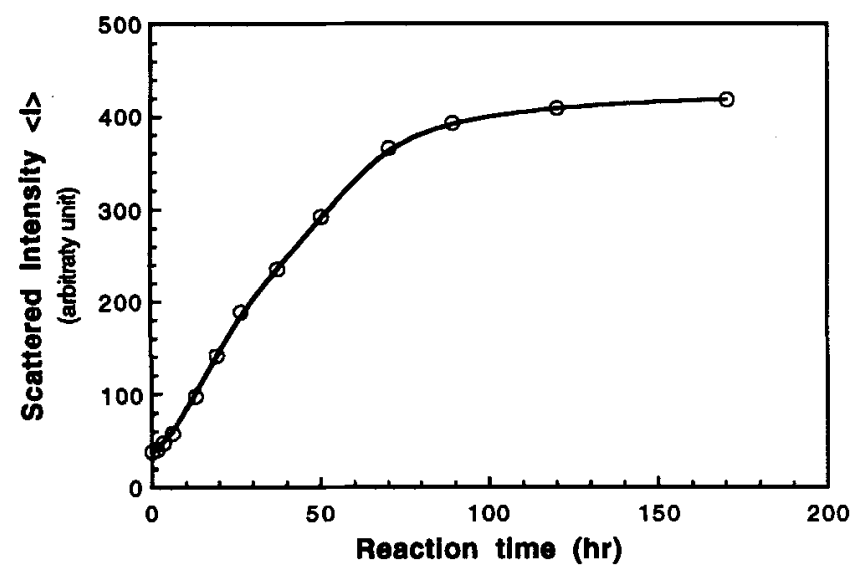

Figure 7. Intensity of light scattered from a microemulsion during TEOS hydrolysis.

The initial solution composition is shown in Figure 2.

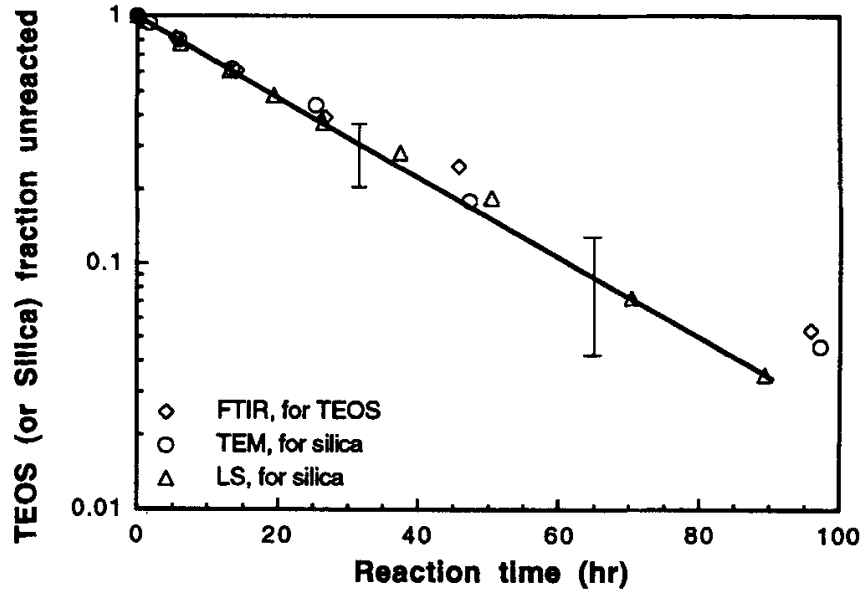

Figure 8. Comparison of the rates of TEOS hydrolysis and silica particle growth in a microemulsion.

Results were replotted from the data shown in Figure 3 (FTIR), Figure 6 (TEM), and Figure 7 (LS).

the steady increase of the scattered light intensity with time also reflects the formation of silica particles in the solution. The rates of decreasing TEOS concentration and increasing silica mass were calculated from the data shown in Figures 3, 6, and 7 using Eqs. 9-11, respectively. As shown in Figure 8, the semilogarithmic plots of these three equations overlap quite well with a linear decay vs. the reaction time. The data points measured at the final reaction period appear more scattered due to the higher relative experimental uncertainty. Using the first four initial data points, the apparent specific rate constants for TEOS hydrolysis $\left(k_{h}\right)$ and silica-particle growth $\left(k_{c}\right)$ were determined to be $0.031 \mathrm{~h}^{-1}\left(k_{h}\right.$, FTIR), $0.032 \mathrm{~h}^{-1}\left(k_{c}\right.$, TEM), and $0.034 \mathrm{~h}^{-1}\left(k_{c}, \mathrm{LS}\right)$, respectively. The fact that the calculated $k_{h}$ and $k_{c}$ values are virtually the same demonstrates that the growth of silica particles is rate controlled by the extremely slow hydrolysis of TEOS. This hydrolysis reaction is carried out through the mass transfer of TEOS molecules from the oil phase into microemulsion droplets. The subsequent contact of TEOS molecules with water forms hydrolyzed silica monomers, which then condense with other silica species.

\section{Kinetics of TEOS hydrolysis}

In this study, the rate of TEOS hydrolysis in microemulsions with different concentrations of water, ammonia and NP4 surfactant was determined by the absorption intensity of the Si-O-C stretching IR band of TEOS located at $967 \mathrm{~cm}^{-1}$.

Effect of Aqueous Ammonia Content. In this experiment the ammonia-to-water molar ratio in the microemulsion sample was maintained at 0.434 . The time evolution of the concentration of TEOS in microemulsions is shown in Figure 9 for different concentrations of aqueous ammonia. It is clear that the rate of TEOS hydrolysis increases with increasing the aqueous ammonia concentration. For each concentration of aqueous ammonia, the logarithm of the TEOS concentration decreases linearly with the reaction time during the early reaction period. Figure 10 shows the calculated apparent rate constant, $k_{h}$, at different concentrations of aqueous ammonia for two NP4 surfactant concentrations, $0.063 \mathrm{M}$ and $0.126 \mathrm{M}$. 


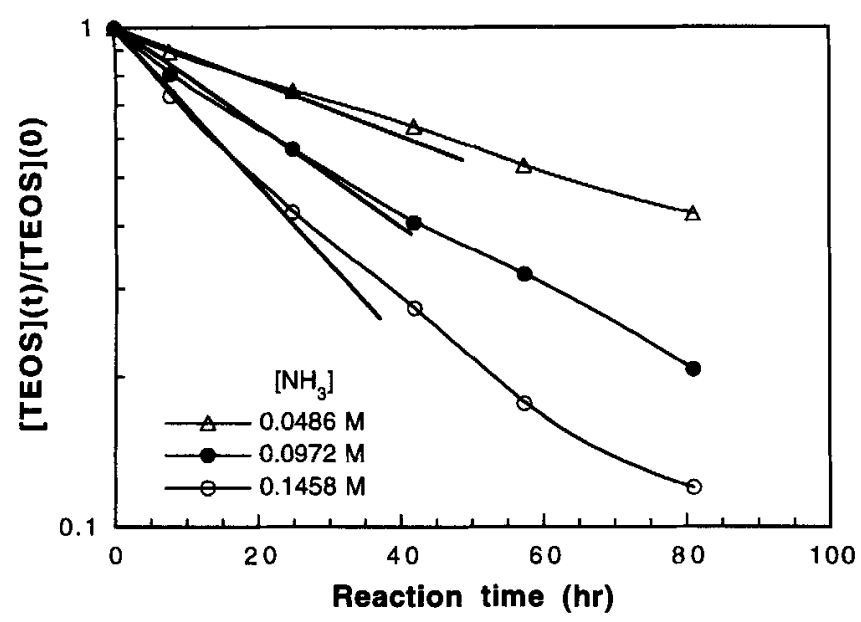

Figure 9. Effect of concentration of aqueous ammonia on the rate of TEOS consumption.

TEOS was hydrolyzed in microemulsions initially contained heptane solvent, $0.126 \mathrm{M} \mathrm{NP4}$, and $0.0298 \mathrm{M}$ TEOS.

For each NP4 concentration, $k_{h}$ increases approximately linearly with the aqueous ammonia concentration, indicating that the rate of TEOS hydrolysis in microemulsions is approximately first order with respect to the concentration of aqueous ammonia.

Effect of Water Concentration. This experiment was performed with the following solution composition: [NP4] $=0.126$ $\mathrm{M},[$ TEOS $]=0.0357 \mathrm{M}$, and $\left[\mathrm{NH}_{3}\right]=0.05 \mathrm{M}$. As illustrated in Figure 11 , the apparent rate constant $k_{h}$ increases only slightly from $0.014 \mathrm{~h}^{-1}$ at $0.115 \mathrm{M} \mathrm{H}_{2} \mathrm{O}$ to $0.0217 \mathrm{~h}^{-1}$ at $0.575 \mathrm{M} \mathrm{H}_{2} \mathrm{O}$, suggesting that water does not significantly affect the rate of TEOS hydrolysis. In order to further analyze the kinetics of TEOS hydrolysis under ammonia catalysis, we assumed that both water and ammonia remained predominantly in the W/O microemulsion droplets without mixing with the oil continuum. Consequently, the concentration of hydroxyl ion $\left(\mathrm{OH}^{-}\right)$in the solution can be calculated by the following equation:

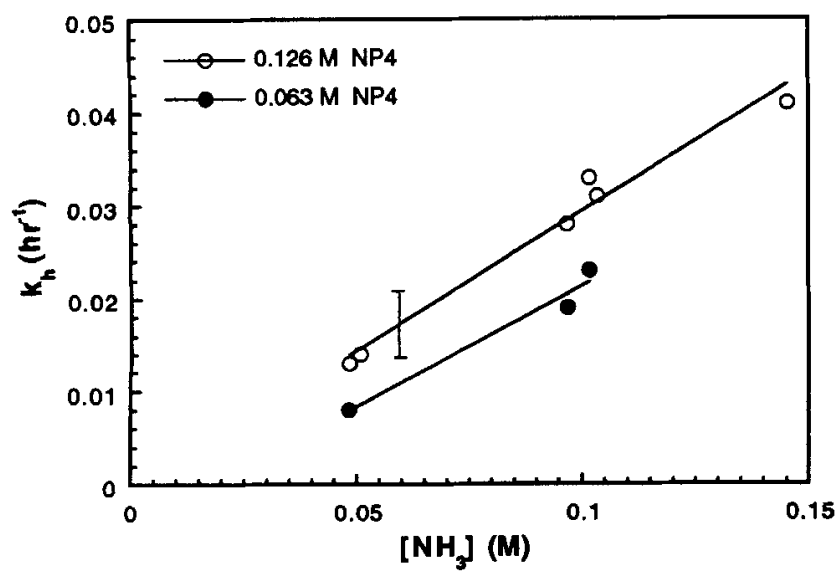

Figure 10. Specific hydrolysis rate constant $k_{h}$ vs. the initial aqueous ammonia concentration.

The initial microemulsions contained heptane solvent, 0.063 or $0.126 \mathrm{M} \mathrm{NP4}$, and 0.0298 or $0.0357 \mathrm{M}$ TEOS,

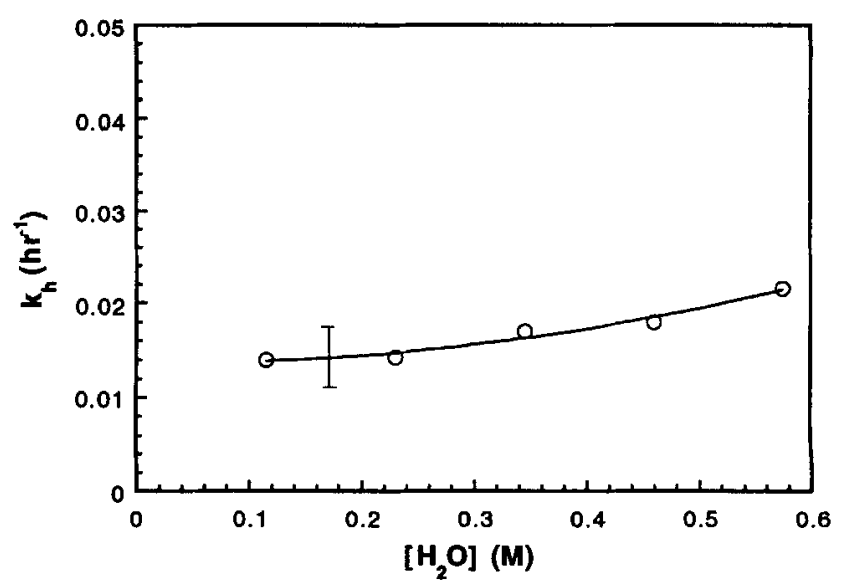

Figure 11. Specific hydrolysis rate constant $k_{h}$ vs. the initial water concentration.

The initial solutions contained heptane solvent, $0.126 \mathrm{M}$ NP4, 0.0357 M TEOS, and 0.05 $\mathrm{M} \mathrm{NH}_{3}$.

$$
\mathrm{NH}_{3}+\mathrm{H}_{2} \mathrm{O} \Leftrightarrow \mathrm{NH}_{4}{ }^{+}+\mathrm{OH}^{-} \quad K_{b}=\frac{\left[\mathrm{NH}_{4}^{+}\right]_{\mathrm{aq}}\left[\mathrm{OH}^{-}\right]_{(\mathrm{aq})}}{\left[\mathrm{NH}_{3}\right]_{(\mathrm{aq})}}
$$

Table 1 lists the calculated $\left[\mathrm{OH}^{-}\right.$] values, the measured $k_{h}$ values and the $k_{h} / \mathrm{OH}^{-}$] ratios. The fact that the $k_{h} / \mathrm{OH}^{-}$] ratio remains essentially constant at around $3.25(\mathrm{M} \cdot \mathrm{h})^{-1}$ indicates that $k_{h}$ has a first-order dependence on the hydroxyl ion concentration, which is consistent with previous observations (Aelion et al., 1950; Keefer, 1984; Ballard and Fanelli, 1993).

Previous studies have also shown that for TEOS hydrolysis in alcohol media, the apparent reaction orders with respect to the concentrations of aqueous ammonia and water were approximately 2.5 and 1.5 , respectively (Byers et al., 1987; Harris et al., 1990; Bogush et al., 1991; Van Blaaderen et al., 1992). However, in W/O microemulsions these reaction orders were found to be about 1 and slightly above 0 , respectively. Therefore, the major difference between the rate of TEOS hydrolysis in microemulsions and in alcohol is the reaction order with respect to the concentration of water. This difference can be explained by the schematics in Figure 12. In W/O microemulsions, both water and ammonia remain associated together in microemulsion droplets; therefore, the microenvironment of ammonia is virtually similar to the aqueous medium and independent of the concentration of water in microemulsion media. However, in alcohol media, water and ammonia are no longer associated together, but are separated and diluted throughout the media by alcohol molecules via strong hydrogen-bonding interactions. Therefore, the water concentration averaged over the entire solution volume is equivalent to the actual concentration of water around each ammonia molecule. As a result, the generation of hydroxyl ions in alcohol media, which requires ammonia to contact with and be hydrolyzed by water, becomes dependent upon the water concentration in the media. In addition, the hydrolysis of TEOS needs a transfer of the ethoxy group from TEOS to water to form ethanol and hydroxyl ion, leading to an even stronger rate dependence of TEOS hydrolysis on the concentration of water in alcohol media (Harris et al., 1990). 
Table 1. Calculated $\left[\mathrm{OH}^{-}\right], k_{h}$ Value, and Synthesized Silica-Particle Number for Microemulsions with Different Initial $\left[\mathrm{H}_{2} \mathrm{O}\right]^{*}$

\begin{tabular}{ccccccc}
\hline $\begin{array}{c}{\left[\mathrm{H}_{2} \mathrm{O}\right]} \\
\mathrm{M}\end{array}$ & $\begin{array}{c}{\left[\mathrm{NH}_{3}\right]} \\
\mathrm{M}\end{array}$ & $\begin{array}{c}{\left[\mathrm{NH}_{3}\right] /} \\
{\left[\mathrm{H}_{2} \mathrm{O}\right]}\end{array}$ & $\begin{array}{c}{\left[\mathrm{OH}^{-}\right]} \\
\mathbf{M}\end{array}$ & $\begin{array}{c}k_{h} \\
\mathrm{~h}^{-1}\end{array}$ & $\begin{array}{c}\text { Particle No. } \\
\left(\times 10^{16} / \mathrm{dm}^{3}\right)\end{array}$ \\
\hline 0.115 & 0.05 & 0.434 & 0.00405 & 0.0140 & 3.45 & 1.359 \\
0.230 & 0.05 & 0.217 & 0.00463 & 0.0143 & 3.09 & 2.196 \\
0.234 & 0.05 & 0.144 & 0.00522 & 0.0170 & 3.26 & 3.890 \\
0.460 & 0.05 & 0.108 & 0.00565 & 0.0180 & 3.62 & \\
0.575 & 0.05 & 0.0869 & 0.00595 & 0.0215 & 3.62 & \\
0.224 & 0.097 & 0.434 & 0.00786 & 0.0285 & 3.700 & \\
0.336 & 0.146 & 0.434 & 0.01183 & 0.041 & 3.46 & \\
\hline
\end{tabular}

*TEOS was hydrolyzed in microemulsions with heptane solvent, 0.126 M NP4 and 0.0357 M TEOS.

Effect of NP4 Surfactant Concentrations. This experiment was performed with the following solution composition: $[\mathrm{TEOS}]=0.0357 \mathrm{M} ;\left[\mathrm{H}_{2} \mathrm{O}\right]=0.235 \mathrm{M}$; and $\left.\left[\mathrm{NH}_{3}\right] / \mathrm{H}_{2} \mathrm{O}\right]=$ 0.434. As shown in Figure 13, the apparent rate constant $k_{h}$ increases from $0.023 \mathrm{~h}^{-1}$ at $0.063 \mathrm{M}$ of NP4 to $0.048 \mathrm{~h}^{-1}$ at $0.252 \mathrm{M}$ of NP4, suggesting that surfactant concentration affects the rate of TEOS hydrolysis in microemulsion solutions. The corresponding apparent reaction order with respect to [NP4] was estimated to be between 0.4 and 0.6 .

The actual mechanism by which NP4 surfactant controls the rate of TEOS hydrolysis in microemulsions is complicated in that the mechanism involves molecular interactions of all species in the media. The most probable mechanism is that NP4 surfactant molecules expedite the molecular contact between TEOS and hydroxyl ions. The head group of NP4 surfactant molecules contains ether $(-\mathrm{O}-)$ groups and a hydroxyl group $(-\mathrm{OH})$, which can hydrogen bond with the hydroxyl ions $\left(\mathrm{OH}^{-}\right)$and the oxygen atoms $(\mathrm{Si}-\mathrm{O}-\mathrm{C})$ of TEOS, respectively. As a result, increasing the surfactant concentration in solution increases the rate of the "successful" molecular contact between TEOS and hydroxyl ion in microemulsion droplets, which leads to the hydrolysis of TEOS. In addition, increasing the concentration of NP4 surfactant can also enlarge the area of the microemulsion droplet surface and favor the higher rate of mass transfer of TEOS into microemulsion droplets.

In a previous study, Arriagada (1991) used TEM to measure the growth of silica particles in W/O microemulsions containing cyclohexane and different concentrations of NP5 surfactant. The effect of surfactant concentration on the rate of silica particle growth found by Arriagada is similar to that on the rate of TEOS hydrolysis observed in this study. This similarity is due to the fact that TEOS hydrolysis is a ratecontrolling step to the growth of silica particles in microemulsions.

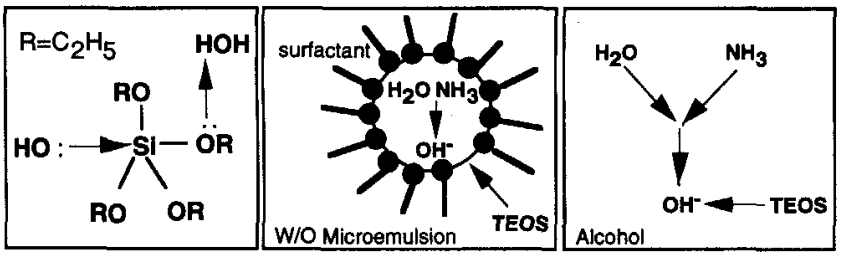

Figure 12. Base-catalyzed hydrolysis of TEOS (left); ammonia-catalyzed TEOS hydrolysis in W/O microemulsions (middle); and in ethanol media (right).

\section{Final size distribution of silica particles}

Transmission electron microscopy was used to quantify the final size of silica particles two weeks after being synthesized in W/O microemulsions containing different concentrations of water and NP4 surfactant. These microemulsions were also used to study the rate of TEOS hydrolysis shown in Figures 11 and 13.

Effect of Water Concentration. The effect of water concentration on the size of synthesized silica particles is illustrated in Figure 14. As water concentration is increased from 0.115 $\mathrm{M}, 0.345 \mathrm{M}$ to $0.575 \mathrm{M}$, the average diameter, $\langle D\rangle$, of silica particles gradually decreases from $42.3,32.9$ to $26.2 \mathrm{~nm}$, and the normalized standard deviation, $\sigma /\langle D\rangle$, increases from $5.5,7$ to $10.5 \%$, respectively.

Because the initial concentration of TEOS is the same in all samples, the decrease in particle size is a result of increasing the number of silica particles synthesized. Table 1 shows the number of silica particles synthesized for a solid density of $2.09 \mathrm{~g} / \mathrm{mL}$ (Arriagada, 1991). The fact that more stable silica particles are produced at higher water concentrations suggests that the nucleation of silica particles is enhanced by water located in microemulsion droplets. Increasing the concentration of water directly increases the hydration of silica species and causes the greater adsorption of surfactants to the silica surface, which leads to a stronger steric stabiliza-

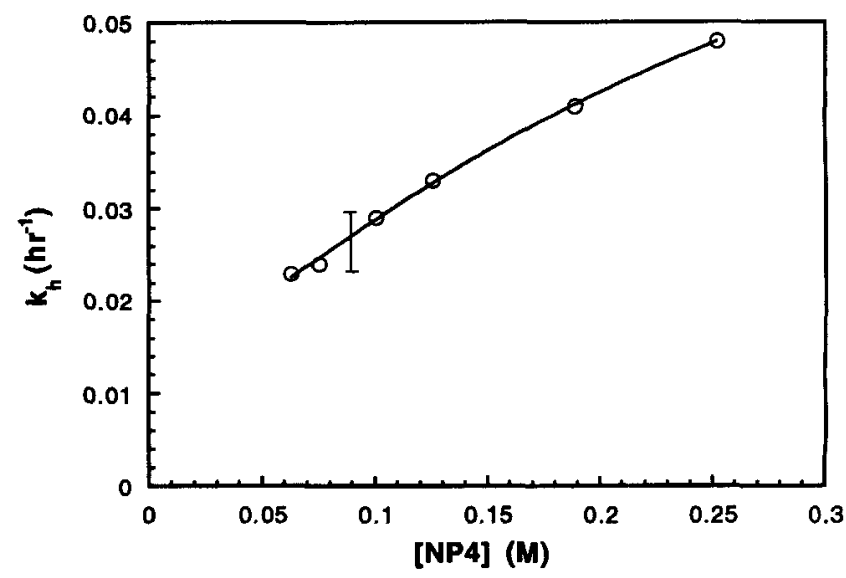

Figure 13. Specific hydrolysis rate constant $k_{h}$ vs. the initial NP4 surfactant concentration.

The initial solutions contained heptane solvent, $0.0357 \mathrm{M}$ TEOS, $0.235 \mathrm{M} \mathrm{H}_{2} \mathrm{O}$, and $\left[\mathrm{NH}_{3}\right] /\left[\mathrm{H}_{2} \mathrm{O}\right]=0.434$. 


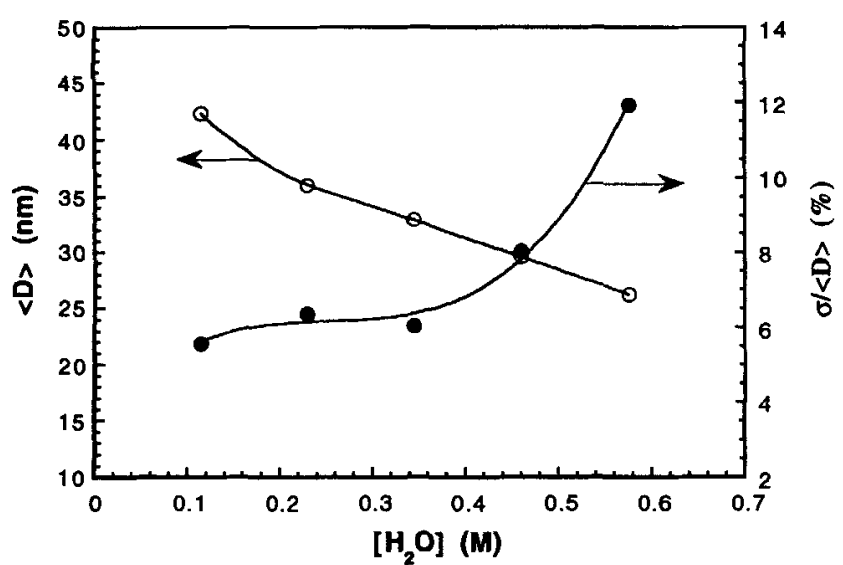

Figure 14. $\langle D\rangle$ and $\sigma /\langle D\rangle$ of final silica particles synthesized at different initial water concentrations.

Same samples were used in measuring the $k_{h}$ values shown in Figure 11.

tion of polymeric silica reacting species during the nucleation period. In addition, the size-independent growth characteristics indicates that the size distribution of silica particles at the end of the reaction should have a similar shape as that immediately after the nucleation period. Therefore, one can expect that $\sigma /\langle D\rangle$ should increase with increasing the ratio of the nucleation time to the entire period of silica particle growth. As shown in Figure 14, the higher $\sigma /\langle D\rangle$ values at higher water concentrations suggests that the nucleation time for silica particles increases as the concentration of water is increased. Overall, it is clear that water plays an essential role in the stabilization of silica particles during their nucleation in $\mathrm{W} / \mathrm{O}$ microemulsions.

Effect of NP4 Surfactant Concentration. The effect of NP4 concentration on the size of synthesized silica particles is illustrated in Figure 15. The average diameter of silica particles decreases from $39 \mathrm{~nm}$ at $0.07 \mathrm{M}$ of NP4 surfactant to 33 $\mathrm{nm}$ at $0.1 \mathrm{M} \mathrm{NP} 4$ and increases slightly to $37 \mathrm{~nm}$ at $0.252 \mathrm{M}$ NP4. The normalized standard deviation decreases signifi-

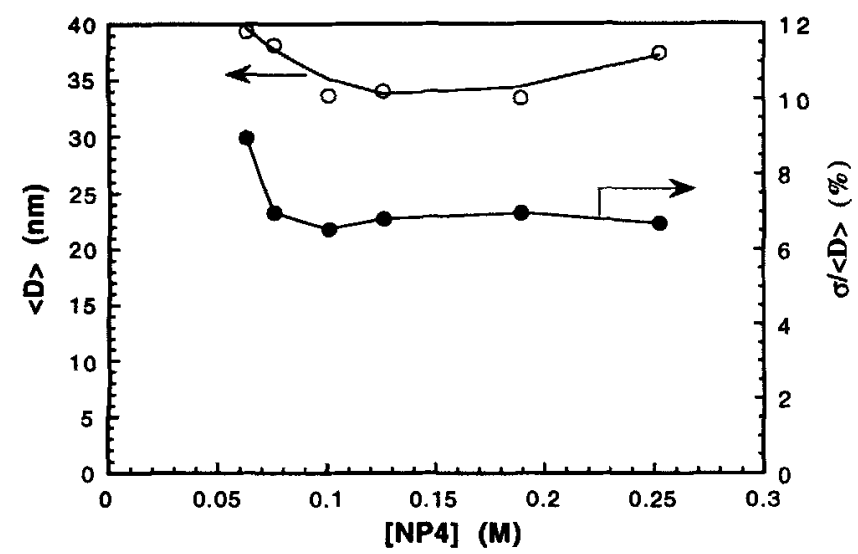

Figure 15. $\langle D\rangle$ and $\sigma /\langle D\rangle$ of final silica particles synthesized at different initial NP4 surfactant concentrations.

Same samples were used in measuring the $k_{h}$ values shown in Figure 13. cantly from $8.9 \%$ at $0.063 \mathrm{M} \mathrm{NP4}$ to $6.8 \%$ at $0.101 \mathrm{M} \mathrm{NP4}$ and then remains unchanged up to $0.252 \mathrm{M} \mathrm{NP4}$. At $0.063 \mathrm{M}$ of NP4 surfactant, the original single-phase microemulsion becomes phase separated in the later reaction period due to the ethanol produced from the hydrolysis of TEOS. Ethanol reduces the water-surfactant association by competing with surfactants to hydrogen-bond water and, therefore, reduces the solubility of water in microemulsions (Osseo-Asare and Arriagada, 1992). The large $\sigma /\langle D\rangle$ value of this sample is evident with approximately $2 \%$ silica particles having abnormally large diameters of $60-80 \mathrm{~nm}$. Because the other microemulsion samples were neither phase separated nor forming abnormally large particles, phase separation is considered to be responsible for the formation of these large particles.

Although $\mathrm{W} / \mathrm{O}$ microemulsions remain single phase be tween NP4 surfactant concentration of $0.0756 \mathrm{M}$ and 0.252 $\mathrm{M}$, the average diameter and the normalized standard deviation of particles reach a minimum in an intermediate NP4 concentration $\left.\left(\left[\mathrm{H}_{2} \mathrm{O}\right] / \mathrm{NP} 4\right]=1.9\right)$. This trend can be explained by the compartmentalization of the silica reacting species in microemulsion droplets while they condense into nuclei. As the concentration of NP4 surfactant is decreased toward the phase boundary value (e.g., $\left[\mathrm{H}_{2} \mathrm{O}\right] /[\mathrm{NP} 4]=3.8$ ), W/O microemulsion droplets become fewer but contain larger aqueous cores. As a result, the condensation of the hydrolyzed silica reacting species is more easily facilitated through intramicellar collisions than through the intermicellar exchange of silica species, thereby forming a smaller number of nuclei. On the other hand, at high NP4 concentrations (e.g., $\left.\left[\mathrm{H}_{2} \mathrm{O}\right] /(\mathrm{NP} 4]=0.95\right)$, most of the water molecules are associated with NP4 surfactant, which results in the reduced hydration of the surface of silica species as well as less surfactants adsorbed to the species. With a weaker steric stabilization by surfactants, silica species exchange more easily between microemulsion droplets and hence form fewer nuclei.

Through the interplay among the FTIR, TEM, and LS techniques, this experimental study quantified the kinetics of TEOS hydrolysis and silica-particle growth in nonionic W/O microemulsions. This analysis of the reaction kinetics not only led to a further understanding of the mechanism of growth of silica particles in microemulsions, but also provided guidelines for controlling the rate of silica-particle synthesis in microemulsions. In addition, the results of this study may be applied to the kinetics study of other types of colloidal formation in W/O microemulsions. For example, this study found that the base-catalyzed hydrolysis of TEOS in microemulsions follows the same nucleophilic substitution reaction as that in alcohol media, which suggests that the acid-catalyzed TEOS hydrolysis in microemulsions (i.e., the electrophilic substitution of TEOS's ethoxy group with hydronium ion, $\mathrm{H}_{3} \mathrm{O}^{+}$(Ballard and Fanelli, 1993)) should display a first-order rate dependence on both $\left[\mathrm{H}_{2} \mathrm{O}\right]$ and $\left[\mathrm{H}^{+}\right]$. The different dependence of the TEOS hydrolysis rate on water concentration in alcohol and in microemulsions also implies that the hydrolysis kinetics of other types of metal alkoxides, such as tetramethyl orthosilicate $\left(\mathrm{Si}\left(\mathrm{OCH}_{3}\right)_{4}\right)$, titanium tetrabutoxide ( $\left.\mathrm{Ti}\left(\mathrm{OC}_{4} \mathrm{H}_{9}\right)_{4}\right)$, may also behave differently in W/O microemulsions and in alcohol media.

The effects of water and surfactant concentrations on the size of silica particles synthesized appear similar for heptane-based nonionic microemulsion systems and for cyclohex- 
ane-based systems. However, the influence of the type of surfactants and oil solvent on the formation of silica particles in microemulsions was not addressed in previous studies and is currently under investigation.

\section{Summary}

The growth of silica particles in nonionic $\mathrm{W} / \mathrm{O}$ microemulsions by ammonia-catalyzed TEOS hydrolysis was found to be controlled by the rate of TEOS hydrolysis. The size distribution of silica particles maintains virtually the same shape over the growth period, which indicates that the intermicellar exchange of hydrolyzed silica reacting species is significantly faster than their condensation to the surface of growing silica particles.

The rate of TEOS hydrolysis in microemulsions is first order with respect to the aqueous ammonia concentration and approximately zero order with respect to water concentration. From the fact that TEOS hydrolysis follows a nucleophilic $\left(\mathrm{S}_{N} 2\right)$ substitution reaction, it is deduced both water and ammonia remain primarily in microemulsion droplets. The rate of TEOS hydrolysis is approximately one-half order with respect to the concentration of surfactant, suggesting that surfactants affect the molecular contact between the hydroxyl ion in microemulsion droplets and TEOS, which diffuses into the droplets from the external oil phase.

The final average size of silica particles synthesized in this microemulsion system ranges from 26 to $43 \mathrm{~nm}$, depending on the concentrations of water and NP4 surfactant. At a constant surfactant concentration, increasing the concentration of water in microemulsions causes a significant reduction of the size and uniformity of silica particles, due to the increase of the stability of hydrolyzed silica species and the extension of the particle nucleation period. Changing the surfactant concentration also influences the size and dispersity of synthesized silica particles. At a given water concentration, the smallest and most uniform silica particles occur at an intermediate water-to-surfactant molar ratio (i.e., 1.9) where both water and surfactant are of sufficient concentrations to compartmentalize silica species in droplets during the particle nucleation period.

\section{Acknowledgment}

The authors express gratitude for the financial support of Department of Energy and the following industrial sponsors: Aramco, ARCO, Chevron, Conoco, Dowell-Schlumberger, Hurriburton Services, Mobil, and Unocal. We also greatly appreciate Professors E. Gulari and F. E. Filisco for allowing us to use FTIR spectrophotometer and LS apparatus.

\section{Literature Cited}

Aelion, R., A. Loebel, and F. Eirich, "Hydrolysis of Ethyl Silicate," J. Amer. Chem. Soc., 17, 5705 (1950).

Arriagada, F. J., "Synthesis of Submicron Particles in Reverse Micellar Systems: Nanosize Silica via Hydrolysis of Tetraethyl Orthosilicate," PhD Thesis, Pennsylvania State Univ., University Park (1991).

Arriagada, F. J., and K. Osseo-Asare, "Synthesis of Nanosize Silica in Aerosol OT Reverse Microemulsions," J. Colloid Interface Sci., 170, 8 (1995).

Ballard, C. P., and A. J. Fanelli, "Sol-Gel Route for Material Synthesis," Chemistry of Advanced Materials: A 'Chemistry for the 21st Century' Monograph, C. N. R. Rao, ed., Blackwell Sci., Boca Raton, FL, p. 1 (1993).

Bergna, H. E., ed., The Colloidal Chemistry of Silica; Advances in Chemistry Series 234, Amer. Chem. Soc., Washington, DC (1994).
Bogush, G. H., and C. F. Zukoski IV, "Studies of the Kinetics of the Precipitation of Uniform Silica Particles through the Hydrolysis and Condensation of Silicon Alkoxides," J. Colloid Interface Sci., 142, 1 (1991).

Bommarius, A. S., J. F. Holzwarth, D. I. C. Wang, and T. A. Hatton, "Coalescence and Solubilizate Exchange in a Cationic Four-Component Micellar System," J. Phys. Chem., 94, 7232 (1990).

Brinker, C. J., and G. W. Scherer, Sol-Gel Science, Academic Press, New York (1989).

Byers, C. H., M. T. Harris, and D. G. Williams, "Controlled Microcrystalline Growth Studies by Dynamic Laser-Light-Scattering Methods," Ind. Eng. Chem. Res., 26, 1916 (1987).

Chang, C. L., "Formation of Silica Particles and Stabilization of Asphaltene Colloids in Apolar Media using Amphiphiles and Polymers," PhD Thesis, Univ. of Michigan, Ann Arbor (1995).

Clark, S. P., D. I. Fletcher, and X. Ye, "Interdroplet Exchange Rates of Water-in-Oil and Oil-in-Water Microemulsion Droplets Stabilized by $\mathrm{C}_{12} \mathrm{E}_{5}$," Langmuir, 6, 1301 (1990).

Colthup, N. B., L. H. Daly, and S. E. Wiberley, Introduction to Infrared and Raman Spectroscopy, 3rd ed., Academic Press, San Diego (1990).

Dirksen, J. A., and T. A. Ring, "Fundamentals of Crystallization: Kinetic Effects on Particle Size Distributions and Morphology," Chem. Eng. Sci., 46(10), 2389 (1991).

Espiard, P., J. E. Mark, and A. Guyot, "A Novel Technique for Preparation Organophilic Silica by Water-in-Oil Microemulsions," Polym. Bull., 24, 173 (1990).

Fendler, J. H., "Atomic and Molecular Clusters in Membrane Mimetic Chemistry," Chem. Rev., 87, 877 (1987).

Harris, M. T., R. R. Brunson, and C. H. Byers, "The Base-Catalysed Hydrolysis and Condensation Reactions of Dilute and Concentrated TEOS Solutions," J. Non-Cryst. Solids, 121, 397 (1990).

Keefer, K. D., "The Effect of Hydrolysis on the Structure and Growth of Silicate Polymers," Better Ceramics Through Chemistry, Vol. 32, C. J. Brinker, D. E. Clark, and D. R. Ulrich, eds., Elsevier, New York, p. 15 (1984).

Kon-no, K., "Properties and Applications of Reversed Micelles," Surface and Colloid Science, Vol. 15, E. Matijevic, ed., Plenum, New York, p. 125 (1993).

Matsoukas, T., and E. Gulari, "Dynamics of Growth of Silica Particles from Ammonia-Catalyzed Hydrolysis of Tetra-ethyl-orthosilicate," J. Colloid Interface Sci., 124, 252 (1988).

Nagy, J. B., E. G. Derouane, A. Gourgue, N. Lufimpadio, I. Ravet, and J. P. Verfaillie, "Physico-Chemical Characterization of Microemulsions: Preparation of Monodisperse Colloidal Metal Boride Particles," Surfactants in Solution, Vol. 10, K. L. Mittal, ed., Plenum, New York, p. 1 (1989).

Osseo-Asare, K., and F. J. Arriagada, "Preparation of $\mathrm{SiO}_{2}$ Nanoparticles in a Non-Ionic Reverse Micellar System," Colloids Surf., 50, 321 (1990).

Osseo-Asare, K., and F. J. Arriagada, "Phase and Dispersion Stability Effects in the Synthesis of Silica Nanoparticles in a Non-Ionic Reverse Microemulsion," Colloids Surf., 69, 105 (1992).

Robinson, B. H., A. N. Khan-Lodhi, and T. Towey, "Microparticle Synthesis and Characterization in Reverse Micelles," Structure and Reactivity in Reverse Micelles, M. P. Pileni, ed., Elsevier, New York, p. 198 (1989).

Stober, W., A. Fink, and E. Bohn, "Controlled Growth of Monodisperse Silica Spheres in the Micron Size Range," J. Colloid Interface Sci., 26, 62 (1968).

Sugimoto, T., "Preparation of Monodispersed Colloidal Particles," Adv. Colloids Interface Sci., 28, 65 (1987).

Van Blaaderen, A., J. Van Geest, and A. Vrij, "Monodisperse Colloidal Silica Spheres from Tetraalkoxysilanes: Particle Formation and Growth Mechanisms," J. Colloid Interface Sci., 154, 481 (1992).

Ward, A. J. I., and S. E. Friberg, "Preparing Narrow Size Distribution Particles from Amphiphilic Association Structures," MRS Bull., 41 (1989).

Yamauchi, H., T. Ishikawa, and S. Kondo, "Surface Characterization of Ultramicro Spherical Particles of Silica Prepared by W/O Microemulsion Method," Colloids Surf., 37, 71 (1989).

Yanagi, M., Y. Asano, K. Kandori, K. Kon-no, and A. Kitahara, Proc. 1986 Shikizai Technical Conf., Osaka, Japan, p. 86 (1986).

Manuscript received Dec. 22, 1995, and revision received Apr. 15, 1996. 